\title{
The Reliability of Berger's TABLE IN ESTIMATING 1-RM AND 10-RM OF THE ELBOW FleXor Muscles in Normal Young Adults
}

\begin{abstract}
Isotonic strength training remains one of the methods of strengthening muscles, as it requires inexpensive materials. The method requires the determination of maximal isotonic strength or one repetition maximum [1-RM] and/or sub-maximal isotonic strength (2-RM-10-RM) of a muscle group in order to know the appropriate resistance to subject the muscle group to, and to monitor strength gains by the muscle group. Berger's table contains percentages for predicting 1-RM-10-RM, and it is intended to improve the efficiency of determining isotonic muscle strength.

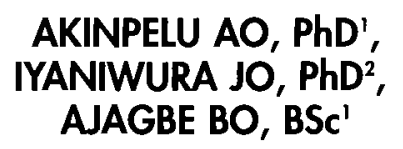

1 Department of Physiotherapy, College of Medicine, University of Ibadan, Ibadan, Nigeria.

2 Department of Statistics, University of Ibadan, Ibadan, Nigeria. The aim of this study was to investigate the reliability of Berger's table in predicting 1-RM and 10-RM of the right elbow flexor muscles.

I-RM and 10-RM were estimated using Berger's table in 100 young adults following the determination of the number of repetitions that could be carried out against randomly selected weights. Weight adjustments were made to obtain the actual 1-RM and 10-RM. Data were subjected to regression analysis. A significant linear relationship exists between the estimated and actual values of 1-RM and 10-RM. Results also showed that Berger's table explains 93\% of 1-RM and 98\% of 10-RM. It was concluded that Berger's table is reliable in determining 1-RM and 10-RM of the elbow flexors in young healthy adults. Regression equations that may improve the accuracy of estimation were derived.
\end{abstract}

\section{KEY WORDS: BERGER'S TABLE, STRENGTH, ISOTONIC, RESISTANCE, MAXIMUM.}

\section{INTRODUCTION}

Many methods have been developed for increasing the strength of skeletal muscles. They include the isotonic, isometric and isokinetic training methods [Kisner and Colby, 1990]. The isotonic and isometric methods require simple and inexpensive materials like metal weights and springs to resist muscular contractions, whereas isokinetic exercises require an electromechanical device. This device keeps the joint motion at a constant predetermined speed thereby varying the resistance through the range of motion. The isokinetic method has been shown to be more efficient in strength training than other training methods [Moffroid et al, 1969, Smith and Melton, 1981]. However, in spite of this advantage, the use of isotonic and isometric training methods still prevails in a great majority of physiotherapy clinics, especially in the developing countries because of the high cost of isokinetic machines. Also, isotonic strength training is still used in research [Housh et al, 1996; Taaffe et al, 1999; Trappe et al, 2000].
Strength measurement is an integral part of muscular training. In the isotonic strength training, muscular strength is often recorded in terms of repetition maximum [RM]. DeLorme [1954] introduced this concept of isotonic strength measurement along with that of heavy resistance-low repetition exercises. One repetition maximum [1-RM] is the maximal load that can be lifted through a complete range of movement once by voluntary contraction of a muscle group. Ten repetition maximum [10-RM] is the maximum load that can be lifted through a complete range of movement by voluntary contraction of a group of muscles 10 consecutive times only [Kisner and Colby, 1990]. Maximal isotonic strength is usually recorded as 1-RM and, isotonic exercise programmes are often based on sub-maximal isotonic strength, 2-RM to $10-\mathrm{RM}$, or a percentage of 1-RM [Housh et al, 1996; Taaffe et al, 1999; Trappe et al, 2000].

Values of repetition maximum are generally determined by the trial and error method [Berger, 1961; Belanger et al, 1984]. This method is time consuming and prone to error due to muscle fatigue. The need to alleviate these problems has long been recognized. Many studies have been carried out in this respect Clark and Herman, 1955; Berger, 1961; Klein and Johnson, 1961; Walsworth et al, 1996]. In one such study, Berger [1961] came up with a table of percentages for estimating any value between 1-RM and 10-RM, when only a value or weight situated between 1-RM and 10-RM is known [Table 1]. Berger [1961] collected his data using the bench press-lift, which involves the pectoralis, triceps anterior deltoid and serratus anterior muscle groups. He however hypothesized that the same proportional result should be obtained with any other muscle group. In 1984, Belanger et al investigated the usefulness of Berger's table for deter-

\section{CORRESPONDENCE TO:}

Dr. (Mrs.) Aderonke O. Akinpelu, Department of Physiotherapy, College of Medicine, University College Hospital, Ibadan, Nigeria 
TABLE 1. Berger's table, an adapted version by Belanger et al [1984]

\begin{tabular}{|c|c|}
\hline Repetition Maximum [RM] & Percentages [\%] \\
\hline 1 & 100.0 \\
\hline 2 & 97.4 \\
\hline 3 & 94.9 \\
\hline 4 & 92.4 \\
\hline 5 & 89.8 \\
\hline 6 & 87.6 \\
\hline 7 & 85.5 \\
\hline 8 & 83.3 \\
\hline 9 & 81.1 \\
\hline 10 & 78.9 \\
\hline
\end{tabular}

Example of the use of the table:

If a subject lifts a weight of $36 \mathrm{~kg} 5$ limes, then

$36 \mathrm{~kg}=5 \mathrm{RM}$.

$5 R M=89.8 \%$ of $1-R M$

$1-\mathrm{RM}=100 / 89.8 \times 36=40 \mathrm{~kg}$

$10-R M=78.9 \%$ of $1-R M$

$10-R M=78.9 / 100 \times 40=31 \mathrm{~kg}$

TABLE 2. Means and standard deviations of 1-RM and 10-RM

\begin{tabular}{|l|l|l|l|l|}
\hline Variables & Mubjects & $\begin{array}{c}\text { Males } \\
\text { (n=50) }\end{array}$ & $\begin{array}{l}\text { Females } \\
\text { (n= 50) }\end{array}$ & \multicolumn{1}{|c|}{$\begin{array}{c}\text { Total } \\
\text { (n= 100) }\end{array}$} \\
\hline Estimated & Mean & 12.23 & $6.98^{*}$ & 9.61 \\
$1-\mathrm{RM}(\mathrm{kg})$ & SD & \pm 1.85 & \pm 1.08 & \pm 3.04 \\
\hline Actual 1-RM & Mean & 13.24 & $7.68^{*}$ & 10.46 \\
(kg) & SD & \pm 1.56 & \pm 0.97 & \pm 3.08 \\
\hline Estimated 10- & Mean & 9.64 & $5.46^{*}$ & 7.55 \\
RM (kg) & SD & \pm 1.43 & \pm 0.80 & \pm 2.40 \\
\hline Actual 10-RM & Mean & 9.74 & 5.57 & 7.65 \\
(kg) & SD & \pm 1.44 & \pm 0.87 & \pm 2.41 \\
\hline
\end{tabular}

Legends

$\mathrm{SD}=$ Standard Deviation

* = Differs significantly $(P<0.05)$ from male value.

FIGURE 1.Test Procedure

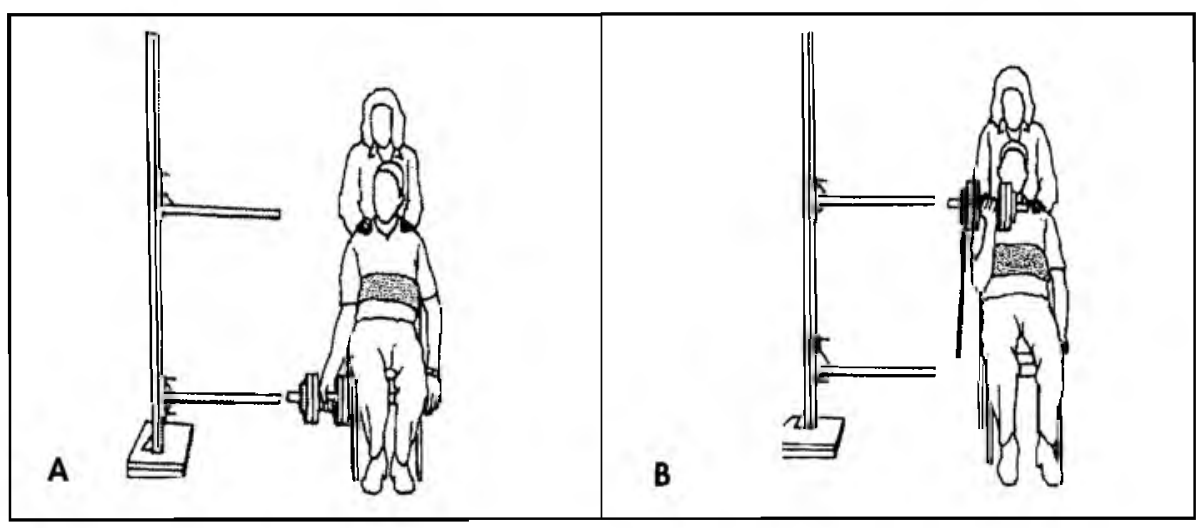

Legends

$A=$ Starting position $\quad B=$ Completion of range mining $1-\mathrm{RM}$ and $10-\mathrm{RM}$ of the knee extensor muscles in normal subjects, and reported high correlation coefficients between the actual values of 1-RM and 10-RM, using Berger's table. They therefore concluded that Berger's table was efficient in determining 1-RM and $10-R M$ of the knee extensor muscles. The present study was carried out to investigate the reliability of Berger's table in estimating values of 1-RM and 10-RM of another group of muscles, the elbow flexor muscles.

\section{MATERIALS AND METHODS}

One hundred volunteers [50 males and 50 females] from the student community of the University College Hospital, Ibadan, Nigeria participated in the study. The volunteers were healthy young adults who were not involved in competitive or regular leisure-time sports (such as weight lifting, squash, lawn/ table tennis, soccer, hand/basket ball). They had no history or obvious evidence of muscular weakness, physical deformities or disabilities. Subjects were right handed and their ages ranged between 20 and 29 years.

The number of times [repetitions] a randomly selected weight could be lifted by active contraction of the right elbow flexor muscles was determined. The instructions were read out to each subject and the test procedure was demonstrated. The subject was made to sit on a chair without armrests. The upper trunk was strapped to the backrest of the chair with a sling, and the shoulders were stabilized by one researcher who stood behind the subject in order to prevent trick movements. The left arm hung loosely by the side. Two horizontal projections from a wooden frame were adjusted to the ends of range of elbow movements while the subject lifted an unloaded barbell. A second observer who sat some distance in front of the subject was able to observe the range of motion. The barbell was then loaded, and subject was instructed to carry out as many lifts as possible [Figure $1 \mathrm{~A} \& \mathrm{~B}$ ]. A weight was considered too heavy when it could not be lifted and too light when the number of lifts exceeded 10. When the load was too heavy, it was decreased; and when it was too light, it 
TABLE 3. Regression Coefficients of Actual 1-RM and 10-RM on Estimated 1-RM and 10-RM

\begin{tabular}{|l|c|c|c|c|c|c|c|}
\hline Subjects & Variable & \multicolumn{2}{|c|}{$\begin{array}{c}\text { Coefficients } \\
\mathrm{a}\end{array}$} & $\mathrm{S} . \mathrm{E}(\mathrm{b})$ & $\mathrm{R} 2$ & T value & P value \\
\hline Male & $1-\mathrm{RM}$ & 4.21 & 0.74 & 0.06 & 0.77 & 12.70 & $<0.0001$ \\
$(\mathrm{n}=50)$ & $10-\mathrm{RM}$ & 0.55 & 1.01 & 0.04 & 0.92 & 23.54 & $<0.0001$ \\
\hline Female & $1-\mathrm{RM}$ & 2.37 & 0.76 & 0.08 & 0.62 & 8.87 & $<0.0001$ \\
$(\mathrm{n}=50)$ & $10-\mathrm{RM}$ & 0.06 & 1.01 & 0.05 & 0.88 & 18.59 & $<0.0001$ \\
\hline Total & $1-\mathrm{RM}$ & 1.03 & 0.98 & 0.03 & 0.93 & 36.99 & $<0.0001$ \\
$(\mathrm{n}=100)$ & $10-\mathrm{RM}$ & 0.15 & 0.99 & 0.02 & 0.98 & 65.88 & $<0.0001$ \\
\hline
\end{tabular}

Legends

$a=$ constant or intercept

$b=$ regression coefficient

S.E. $(b)=$ standard error of $b$

R2 = the coefficient of determination

Regression equations $(y=a+b x)$ for the total sample $(n=100)$

Actual 1-RM $=1.03+0.98$ estimated 1-RM

Actual $10-\mathrm{RM}=0.15+0.99$ estimated $10-\mathrm{RM}$.

TABLE 4. Multiple Regression Coefficients Of Actual 1-RM and 10-RM On Sex and Estimated 1-RM and 10-RM

\begin{tabular}{|l|c|l|l|l|l|}
\hline Variable & Coefficients & R2 & S.E. & T value & P value \\
\hline Constant & 2.65 & & 0.33 & 8.07 & $<0.0001(\mathrm{~S})$ \\
\hline Sex & 1.68 & & 0.27 & 6.18 & $<0.0001(\mathrm{~S})$ \\
\hline Est. 1-RM & 0.73 & 0.95 & 0.55 & 16.17 & $<0.0001$ (S) \\
\hline Constant & 0.23 & & 0.18 & 1.28 & 0.213 (NS) \\
\hline Sex & 0.09 & & 0.15 & 0.60 & 0.551 (NS) \\
\hline Est. 10-RM & 0.98 & 0.98 & 0.03 & 31.08 & $<0.0001(\mathrm{~S})$ \\
\hline
\end{tabular}

Legend

R2 = Coefficient of determination

S.E. = Standard error of estimate

$S=$ Significant

NS = Not significant

Est. $=$ estimated

Regression equation for $1-R M(y=a+b 1 s 1+b 2 s 2)=$

Actual 1-RM $=2.65+1.68+0.73$ estimated 1-RM.

(Where $y=$ actual $1-R M, a=$ the constant, $b 1=$ the regression coefficient for sex,

s1 = the dummy value for sex, which is 0 for female and 1 for male,

b2 = coefficient of standard error, and s2 = estimated 1-RM).

was increased. The test was then repeated after a 10-minute rest. Whenever the need arose to adjust the weight more than twice, the subject was given another appointment and the test was repeated one or two days after the first visit. When the number of lifts carried out against the weight was between 1 and 10 , the weight in kilograms and the number of repetitions were used to calculate 1-RM and 10-RM, using Berger's table [Table 1].

The actual 1-RM of the muscle group was determined during another visit, 1 to 2 days after the last one. The calculated or estimated 1-RM was used as the baseline weight. The weight was adjusted until the actual 1-RM was obtained. During another visit, also 1 to 2 days after the last visit, the actual 10-RM was similarly determined.

\section{Statistical Analysis:}

The means and standard deviations of 1-RM and 10-RM [estimated and actual] were calculated for the total sample and according to gender. Pearson's correlation coefficient was calculated to determine the relationship between estimated and actual values of 1-RM and 10-RM respectively. Scatter graphs were also plotted. In addition, regression methods were used to analyze the relationship between estimated and actual values of 1-RM and 10-RM respectively. A prediction model with an intercept was used in the analysis. In order to determine whether it was necessary to include gender as a predictor variable, data for males and females were analysed separately, and appropriate equations for predicting actual values for estimated values were derived. Regression analysis was done using the EPI 6 statistical package.

\section{RESULTS}

The mean age of the subjects was 22.8 $[\mathrm{SD}=2.0]$ years. Their mean weight was $59.5[\mathrm{SD}=8.9] \mathrm{Kg}$.; and their mean height was 169.0 [SD $=8.6] \mathrm{cm}$. The male subjects were aged 23.4 [SD $=2.3$ ] years and the females were aged 22.1 $[\mathrm{SD}=1.5]$ years. The mean weight $(64.0[\mathrm{SD}=7.3] \mathrm{kg})$ and height $\{175.1$ $[\mathrm{SD}=6.1] \mathrm{cm}$. $\}$ of the male subjects were significantly higher than the respective values of $55.0[\mathrm{SD}=8.2] \mathrm{kg}$ and $162.9[\mathrm{SD}=8.6] \mathrm{cm}$ for the female subjects $[\mathrm{p}<0.05]$.

The mean value of the estimated 1-RM of the right elbow flexor of the total study sample was $9.61 \mathrm{~kg}$, while for the actual 1-RM, it was $10.46 \mathrm{~kg}$. The estimated and actual 10-RM values were $7.55 \mathrm{~kg}$ and $7.65 \mathrm{~kg}$ respectively [Table 2]. The mean 1-RM and 10-RM (estimated and actual) of the male subjects were significantly higher than those of female subjects $[<0.05]$ as shown in Table 2.

The correlation coefficient between estimated and actual values of 1-RM was 0.97 , and that between estimated and actual values of 10-RM was 0.99 . 
FIGURE 2. Scatter graph for 1-RM

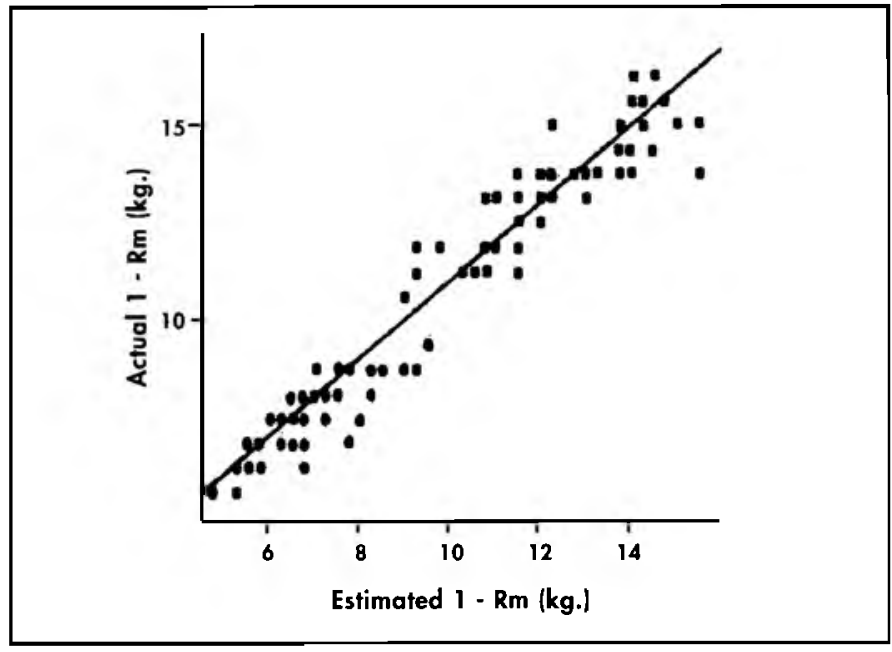

Legends

घ = Male $\quad$ = Female
FIGURE 3.Scatter graph for 10-RM

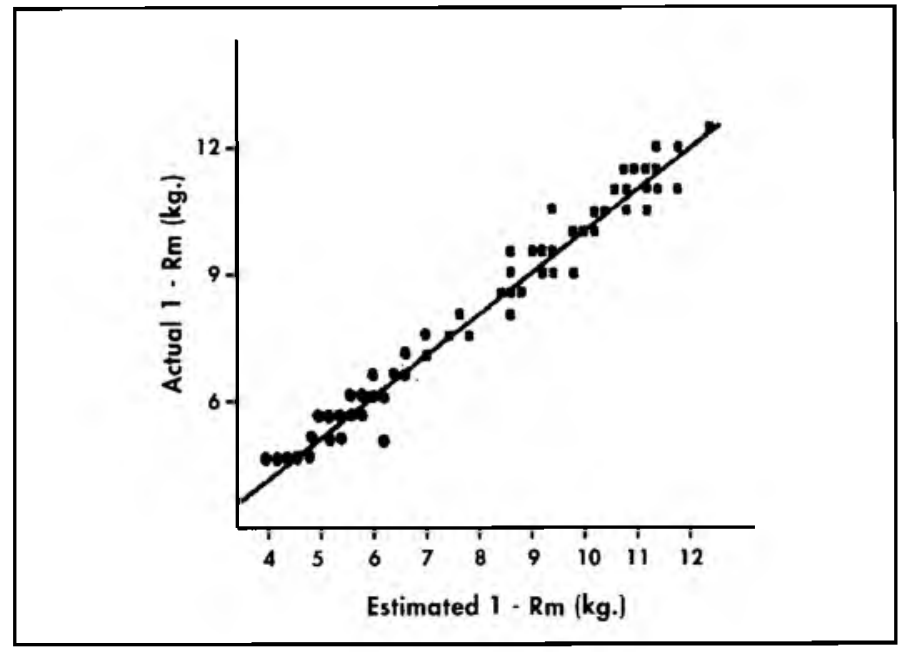

Legends

- Male $\quad$ = Female
Figures 2 and 3 show a linear relationship between the estimated and actual values of 1-RM and 10-RM of subjects' elbow flexor muscles. The intercept [a] of the regression line for $1-\mathrm{RM}$ (total $\mathrm{n}$ ) was 1.03 and the regression coefficient [b] was 0.98 . The coefficient of determination [R2] was 0.93 . The intercept and regression coefficient of 10-RM (regression line) were 0.15 and 0.99 respectively, and R2 was 0.98. Regression analysis indicated a significant relationship between estimated and actual values of each variable $[\mathrm{p}<0.0001]$ as shown in Table 3. Table 3 also shows the regression coefficients of actual I-RM and 10-RM on estimated 1-RM and 10-RM of the elbow flexor muscles for each sex. These coefficients were significant in all instances [p $<0.0001]$. Table 4 shows multiple regression analysis of actual 1-RM and 10-RM on sex and estimated 1-RM and 10-RM. Results indicated that for 1-RM, there was significant difference between the regression coefficients of the two sexes, hence the need to include sex as a predictor variable. For $10-\mathrm{RM}$, the regression analysis for male and female subjects was not significantly different. Therefore, as shown in Table 4, the appropriate equation for predicting actual 1-RM from estimated 1-RM is:

Actual $1-\mathrm{RM}=2.65+1.68 \mathrm{sex}+0.73$ estimated 1-RM.

(Where the dummy values for sex is 0 for females and 1 for males).

Similarly, the appropriate equation for predicting actual 10-RM from estimated 10-RM is:

Actual 10-RM $=0.15+0.99$ estimated 10-RM.

\section{DISCUSSION}

The results of this study indicate that a significant linear relationship exists between the actual and estimated 1-RM and 10-RM using the Berger's table. Based on the coefficients of determination [R2] obtained in this study, Berger's table appears reliable in estimating values of 1-RM and 10-RM of the elbow flexor muscles in normal young adults. The findings of the present study agreed with those by Belanger et al [1984] who also found Berger's table efficient in estimating values of 1-RM and 10-RM of the knee extensor muscles. The study by Belanger et al [1984] and the present study found Berger's table reliable in estimating values of repetition maximum of two different muscle groups and would appear to support the notion that such data could be obtained for other muscle groups.

The male subjects in this study recorded significantly higher values of both 1-RM and 10-RM of the elbow flexor muscles than the female subjects. This is in agreement with the wellknown fact that men generally have more muscular strength than women, and was also corroborated by the significant difference in the mean weight of $64.0 \mathrm{~kg}$ for the male subjects compared with $55.0 \mathrm{~kg}$ for the females. Multiple regression results indicate gender as the predictor variable in the equation for predicting the actual I-RM from estimated I-RM, but not in the equation for predicting the actual 10-RM from estimated 10-RM. This suggests that the strength difference between males and females is higher at maximal effort than at sub-maximal effort. The regression equations derived from this study could further improve the accuracy of estimating repetition maximum values. Further studies would need to focus on the clinical application of our results in various neuromuscular disorders.

\section{CONCLUSION}

Our results confirm that Berger's table is reliable in estimating 1-RM and 10-RM of the elbow flexor muscles in normal young adults. The accuracy of estimation may be further improved by using the regression equations:

1) Actual 1-RM $=2.65+1.68$ sex +0.73 estimated 1-RM

(Where the dummy value of sex equals 1 for male and 0 for females).

2) Actual 10-RM $=0.15+0.99$ estimated 10-RM.

\section{ACKNOWLEDGEMENT}

We acknowledge the contributions of Prof. E. A. Bamgboye and Mr. D. Kangave during the preparation of the manuscript. Mrs. Funlola Ashebu assisted with translating the paper by Belanger and associates from French to English. 


\section{REFERENCES}

Belanger A.Y Noel G, Bilodean 1, Bouton A, Gingras C, Guillement S, 1984 L'utilisation de la table Berger pour determiner le 1-RM et le 10-RM des muscles extensors du genou. Physiotherapy Canada 35:11-15.

Berger R A 1961 Determination of resistance loan for 1-RM and 10-RM. Journal of the Association of Physical and Mental rehabilitation 51:100-110,117

Clark D H, Herman E L 1961 Objective determination of resistance load for ten repetition maximum for quadriceps development. Research Quarterly 26:385-390.

DeLorme T F 1954 Restoration of muscle power by heavy resistance exercises. Journal of Bone and Joint Surgery 27:645-649.
Housh T J, Housh D J, Weir J P, Weir L L 1996 Effects of unilateral concentrically dynamic constant external resistance training. International Journal of Sports Medicine 17 (5): $338-343$

Kisner C, Colby L A 1990 Therapeutic Exercise - Foundations and Techniques 2nd ed, F A Davis, Philadelphia: 88-92.

Klein K K Johnson E 1961 A method of determining the maximum load for ten repetitions in progressive resistance exercise for quadriceps development. Journal of the Association of Physical and Mental Rehabilitation 7:4

Moffroid M, Whipple R, Hofkosh J, Thistle H 1969 A study of isokinetic exercise. Physical Therapy 49: 735-737.

Smith M J, Melton P 1981 Isokinetic vs. isotonic variable-resistance training. American Journal of Sports Medicine 9: 275 - 279.
Taaffe D R, Duret C, Wheeler S, Marus R 1999 Once weekly resistance exercise improves strength and neuromuscular performance in older adults. Journal of American Geriatrics Society $47(10): 1208-1214$

Trappe S, William D, Gordon M, Porte D, Roweten G, Costil D 2000 Effect of resistance training on single muscle fibre contractile function in older men. Journal of Applied Physiology 89 (I): $143-152$.

Walsworth M, Schneider R, Schultz J, Dahl C Allison S, Underwood F, Freund J 1998 Prediction of 10 repetition maximum for short-arc quadriceps exercise from hand-held dynamometer and anthropometric measurements. Journal of Orthopaedic and Sports Physical Therapy 28(2): $97-104$.

\section{New Millennium Time to think of a change?}

Quality Locums are looking for quality personnel in all grades and specialities for work in the UK. Eligibility for a visa or work permit would be an advantage, but even if you are not eligible we would still like to hear from you as we may be able to

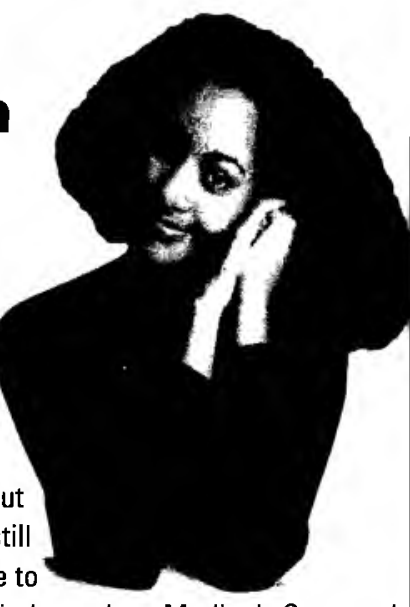
help. Quality Locums are the largest independent Medical, Care and Education Agency in the UK and we have branches in South Africa and Australia. We need Medical Staff of all specialities, Social Workers and Teachers urgently to fill full and part time positions throughout Great Britain and Ireland. We are experts at helping you to take advantage of the opportunities in the UK. Why not call one of our managers today for an informal discussion.

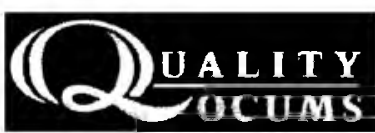

Sonja Lewis Quality Locums Cape Town Tel: 0214625357

Fax: 0214625390

Email: QualityLocums@WorIdonline.co.za

Matt Wagner Quality Locums Durban

Tel: 0314692098

Email: Wagner@yebo.co.za

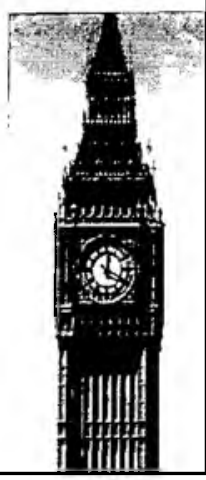

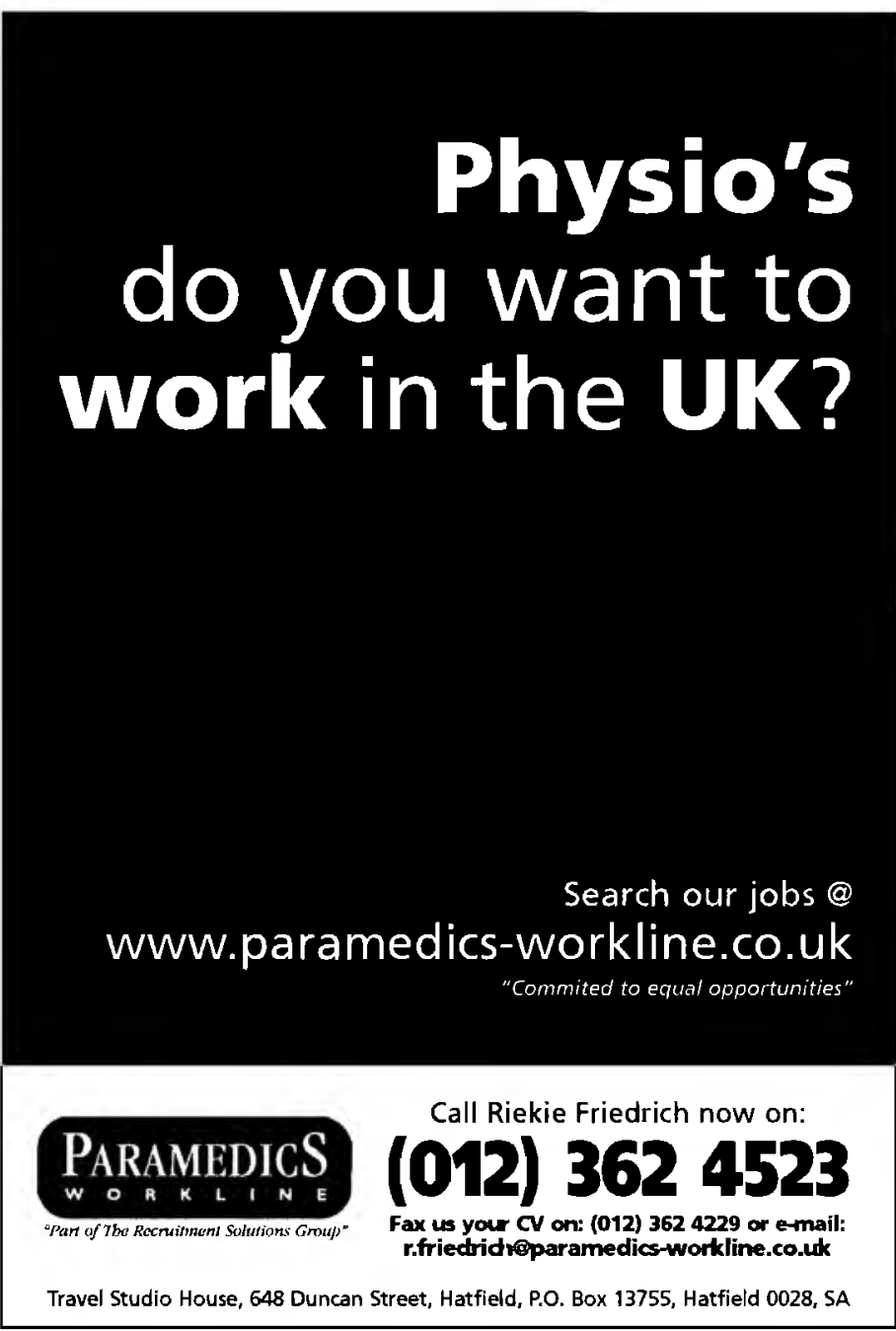

Search our jobs@
Workine.co.uk

Call Riekie Friedrich now on ax us your CV on: (012) 3624229 or email: r.friedridmapamedics-workline.co.uk

Travel Studio House, 648 Duncan Street, Hatfield, P.O. Box 13755, Hatfield 0028, SA 